\title{
Inhibition of MDA-MB-231 breast cancer cell migration and invasion activity by andrographolide via suppression of nuclear factor- $\kappa B$-dependent matrix metalloproteinase-9 expression
}

\author{
ZANJING ZHAI $^{1 *}$, XINHUA QU ${ }^{1 *}$, HAOWEI LI $^{1 *}$, ZHENGXIAO OUYANG $^{1,2}$, WEI YAN $^{3}$, \\ GUANGWANG LIU ${ }^{4}$, XUQIANG LIU ${ }^{1}$, QIMING FAN ${ }^{1}$, TINGTING TANG $^{1}$, KERONG DAI $^{1}$ and AN QIN ${ }^{1}$ \\ ${ }^{1}$ Shanghai Key Laboratory of Orthopaedic Implants, Department of Orthopaedics, Ninth People's Hospital, \\ Shanghai Jiao Tong University School of Medicine, Shanghai 200011; ${ }^{2}$ Department of Orthopaedics, \\ Affiliated Tumor Hospital of Xiangya School of Medicine, Central South University, Changsha, \\ Hunan 410013; ${ }^{3}$ Department of Orthopaedics, Wendeng Zhenggu Hospital of Shandong Province, \\ Weihai, Shandong 264400; ${ }^{4}$ Department of Orthopedic Surgery, The Central Hospital of Xuzhou, \\ Affiliated Hospital of Medical College of Southeast University, Xuzhou, Jiangsu 221009, P.R. China
}

Received December 2, 2013; Accepted July 25, 2014

DOI: $10.3892 / \mathrm{mmr} .2014 .2872$

\begin{abstract}
Breast cancer is one of the most common types of cancer worldwide. The majority of patients with cancer succumb to the disease as a result of distant metastases (for example, in the bones), which cause severe complications. Despite advancements in breast cancer treatment, chemotherapeutic outcomes remain far from satisfactory, prompting a search for effective natural agents with few side-effects. Andrographolide (AP), a natural diterpenoid lactone isolated from Andrographis paniculata, inhibits cancer cell growth. The current study aimed to examine the effect of AP on breast cancer cell proliferation, survival and progression in vitro and also its inhibitory activity on breast cancer bone metastasis in vivo. To achieve this, CCK8, flow cytometry, migration, invasion, western blot, PCR and luciferase reporter assay analyses were performed in vitro as well as establishing intratibial xenograft model of breast cancer bone metastasis in vivo. The results demonstrated that AP inhibits the migration and invasion of the MBA-MD-231 aggressive breast cancer cell line at non-lethal concentrations, in addition to suppressing proliferation and inducing apoptosis at high concentrations in vitro. In vivo, AP significantly inhibited the growth of tumors planted in bone and attenuated
\end{abstract}

Correspondence to: Dr An Qin or Dr Kerong Dai, Shanghai Key Laboratory of Orthopaedic Implants, Department of Orthopaedics, Ninth People's Hospital, Shanghai Jiao Tong University School of Medicine, 639 Zhizaoju Road, Shanghai 200011, P.R. China

E-mail: dr.qinan@gmail.com

E-mail:krdai@163.com

*Contributed equally

Key words: breast cancer, MBA-MD-231, andrographolide, invasion, matrix metalloproteinase- 9 , nuclear factor $\kappa \mathrm{B}$ cancer-induced osteolysis. Tartrate-resistant acid phosphatase staining revealed osteoclast activation in tumor-bearing mice and AP was observed to attenuate this activation. The anti-tumor activity of AP in vitro and in vivo correlates with the downregulation of the nuclear factor $\mathrm{\kappa B}$ signaling pathway and the inhibition of matrix metalloproteinase-9 expression levels. These results indicate that AP may be an effective anti-tumor agent for the treatment of breast cancer bone metastasis.

\section{Introduction}

Breast cancer bone metastasis causes serious complications, including chronic pain and pathologic fractures, which severely reduce quality of life (1). Bone metastasis secondary to breast cancer is associated with a poor prognosis (2) and current therapies for the management of metastasis and osteolysis are far from satisfactory. Hence, it is necessary to develop novel alternative therapies with improved efficacy and fewer side-effects.

Metastasis is a complicated process, which proceeds through a sequence of cancer cell proliferation, adhesion, invasion and migration $(3,4)$. Matrix metalloproteinases (MMPs) are thought to be critical to this process (5-7) and MMP-9 is considered to be the most relevant for tumor invasion (8). MMP regulation occurs at multiple levels and a number of stimuli activate MMP-9, including growth factors, cytokines and phorbol 12-myristate 13-acetate (PMA) (9-11). The MMP-9 promoter contains multiple DNA binding sites for transcription factors, including nuclear factor $\mathrm{\kappa B}(\mathrm{NF}-\mathrm{\kappa B})$ (12). Therefore, the downregulation of MMP-9 expression may be a useful strategy for tumor metastasis intervention. Plant-derived compounds with a chemopreventive potential have been shown to inhibit the invasiveness of several types of cancer by modifying MMP-9 expression $(13,14)$.

Andrographolide (AP) is a diterpenoid lactone isolated from the traditional Chinese and Indian medicinal plant Andrographis paniculata and it is widely used for its efficacy and favorable safety profile in a number of diseases $(15,16)$. 
AP has gained attention for its anticancer $(17,18)$, anti-inflammation $(19,20)$, hepatoprotection $(21,22)$ and anti-infection $(16)$ activities. Previous studies have demonstrated the anti-cancer effect of AP in the MCF-7 and TD-47 breast cancer cell lines (23-25); however, the effect of AP on the more aggressive MDA-MB-231 cancer cell line and on breast cancer bone metastasis in vivo has not been reported.

The aim of the present study was to identify supplementary therapeutic strategies for the treatment of breast cancer metastasis and osteolysis through the investigation of the in vitro action of AP on the invasion and migration of MDA-MB-231 cells. In addition, the efficacy of AP in the prevention of breast cancer bone metastasis and osteolysis were investigated in an in vivo mouse xenograft model.

\section{Materials and methods}

Media and reagents. AP and PMA were purchased from Sigma-Aldrich (St. Louis, MO, USA). Minimum Essential Medium- $\alpha(\alpha$-MEM), fetal bovine serum (FBS) and penicillin were obtained from Gibco-BRL (Gaithersburg, MD, USA). The Cell Counting kit (CCK)-8 assay was purchased from Dojindo Molecular Technology (Tokyo, Japan). Primary antibodies (monoclonal rabbit antibody; species reactivity, human) for $\beta$-actin, phospho-I $\mathrm{B} \alpha, \mathrm{I} \kappa \mathrm{B} \alpha$ and MMP-9 were purchased from Cell Signaling Technology, Inc. (Beverly, MA, USA). The Luciferase Assay system was from Promega (Sydney, Australia). Tris, glycine, $\mathrm{NaCl}, \mathrm{SDS}$, and other reagents were from Sigma-Aldrich. The Vybrant ${ }^{\circledR}$ Apoptosis Assay kit \#2 was from Invitrogen (Carlsbad, CA, USA).

Cell viability assay. MDA-MB-231 cells were cultured in L-15 Medium (Gibco Life Technologies, Beijing, China) with $10 \%$ FBS and maintained in a humidified atmosphere of $5 \%$ $\mathrm{CO}_{2}$ at $37^{\circ} \mathrm{C}$. The complete medium was changed every other day. The cells were treated with increasing concentrations of AP $(0,7.5,15,30,60$ or $120 \mu \mathrm{M})$ for two days prior to the cell viability assays. The anti-proliferative effect of AP on MDA-MB-231 cells was assessed using CCK-8. Briefly, following treatment, $10 \mu \mathrm{l}$ CCK- 8 solution was added to each well and incubated for $4 \mathrm{~h}$. The absorbance was measured at a wavelength of $450 \mathrm{~nm}$ using a ELX800 absorbance microplate reader (BioTek Instruments, Inc., Winooski, VT, USA) at a wavelength of $450 \mathrm{~nm}$ (reference, $650 \mathrm{~nm}$ ). The effect of AP on cell viability was expressed as a percentage of cell viability, with the vehicle-treated control cells set as $100 \%$.

Apoptosis assay. AP induction of apoptosis in MBA-MD-231 cells was determined with the Vybrant ${ }^{\circledR}$ Apoptosis Assay kit \#2. Following treatment, cells were washed twice with cold phosphate-buffered saline (PBS) and resuspended in $1 \mathrm{X}$ Annexin-binding buffer. Early apoptosis was detected via staining with Alexa Fluor ${ }^{\circledR} 488$ Annexin V and propidium iodide. Fluorescence-activated cell sorting was performed using a FACScan ${ }^{\mathrm{TM}}$ flow cytometer and data were acquired using CellQuest software, version 3.0 (BD Biosciences, Sunnyvale, CA, USA).

Migration assay. Transwell ${ }^{\circledR}$ Permeable Supports (Corning Inc., Acton, MA, USA), 24-well chambers with $8-\mu \mathrm{m}$ pore polycarbonate filters, were used as described by the manufacturer. MDA-MB-231 cells $\left(5 \times 10^{4}\right)$ were placed in $100 \mu \mathrm{l}$ serum-free medium in the presence or absence of AP and $600 \mu \mathrm{l}$ complete medium with $80 \mathrm{nM}$ PMA was placed into the lower wells. Following treatment, cells were fixed with $100 \%$ methanol for $20 \mathrm{~min}$ and stained with Trypan blue for $30 \mathrm{~min}$. Non-migrating cells on the upper side of the filter were removed with cotton swabs. Migration was quantified by counting the number of cells on the lower surface of the filter.

Invasion assay. BioCoat ${ }^{\mathrm{TM}}$ Matrigel $^{\mathrm{TM}}$ Invasion Chamber (BD Biosciences), 24-well chambers with $8-\mu \mathrm{m}$ pore polycarbonate filters, were used according to the manufacturer's instructions. MDA-MB-231 cells $\left(5 \times 10^{4}\right)$ were placed in $100 \mu 1$ serum-free medium in the presence or absence of AP, and $600 \mu$ l complete medium with $80 \mathrm{nM}$ PMA was placed in the lower wells. Following treatment, cells on the upper side of the filters were removed. Invading cells on the underside of the filter were fixed with $100 \%$ methanol for 2 min and stained with Liu's stain for $2 \mathrm{~min}$. Invasion was quantified by counting the number of cells on the lower surface of the filter.

Intratibial xenograft model of breast cancer bone metastasis. BALB/c nu/nu mice (Harlan, Indianapolis, IN, USA) were housed in individual cages, maintained in an animal facility under controlled temperature $\left(22-24^{\circ} \mathrm{C}\right)$ and humidity (50-60\%) conditions and a $12 \mathrm{~h}$ light/dark cycle with free access to food and water. Cultured MDA-MB-231 cells were resuspended in PBS at a density of $5 \times 10^{6}$ cells $/ \mathrm{ml}(26,27)$. An aliquot $(10 \mu \mathrm{l})$ of the cell suspension was slowly injected through the anterior tuberosity of the proximal tibia in the right limbs of 5- to 6-week-old female $\mathrm{BALB} / \mathrm{c}$ nu/nu mice (Harlan, Indianapolis, IN, USA). The mice were randomly assigned to vehicle $(0.9 \% \mathrm{NaCl}, \mathrm{n}=8)$ or $\mathrm{AP}$ ( $50 \mathrm{mg} / \mathrm{kg}$ body weight vehicle, $\mathrm{n}=8$ ) groups and treated via an intraperitoneal injection every other day. After 28 days, a bioluminescence assay was performed and fluorescence intensity was quantified (Living Image v3.2, Caliper; Caliper Life Sciences, Hopkinton, MA, USA). Radiographs using the Directview Vita CR system. (Carestream Kodak, Rochester, NY, USA) of the tibiae were obtained prior to euthanasia with ketamine, administered by intraperitoneal injection $(0.8 \mathrm{ml} / 100 \mathrm{~g}$ body weight). The product from Carestream Kodak was. Tissues were removed and fixed in $4 \%$ paraformaldehyde for 1 day at $4{ }^{\circ} \mathrm{C}$ followed by decalcification in $12 \%$ EDTA. Decalcified bones were paraffin-embedded and sectioned. Samples were subjected to tartrate-resistant acid phosphatase (TRAP) staining to identify osteoclasts on the bone surface. Immunostaining for Ki67 (Dako, Carpinteria, CA, USA) and terminal deoxynucleotidyl transferase-mediated dUTP nick-end labeling (TUNEL) were performed as previously described $(28,29)$. Ki67- and TUNEL-positive tumor cells were counted and the percentages of positive cells were calculated. This study was approved by the ethics committee of Shanghai Ninth People's Hospital Affiliated to Shanghai Jiao Tong University School of Medicine (Shanghai, China).

RNA isolation and reverse transcription-quantitative polymerase chain reaction $(R T-q P C R)$. RNA isolation was performed as previously described (30). Total RNA was extracted using the Qiagen RNeasy Mini kit (Qiagen, 


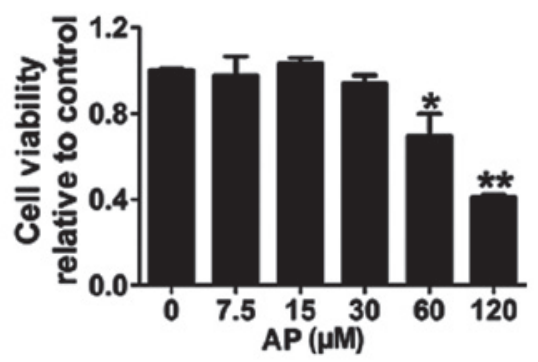

C
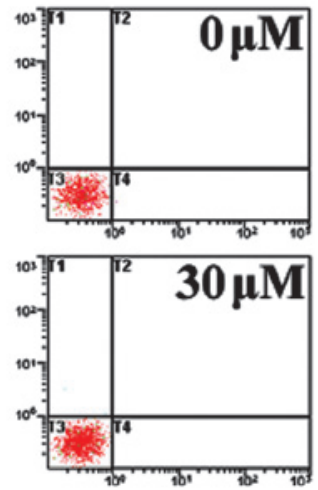
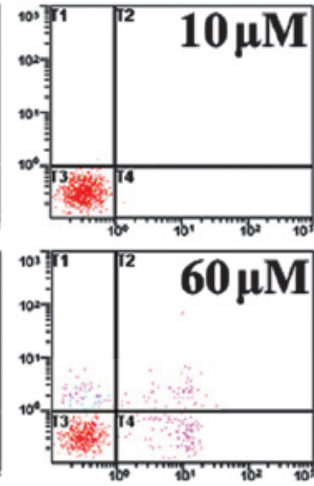

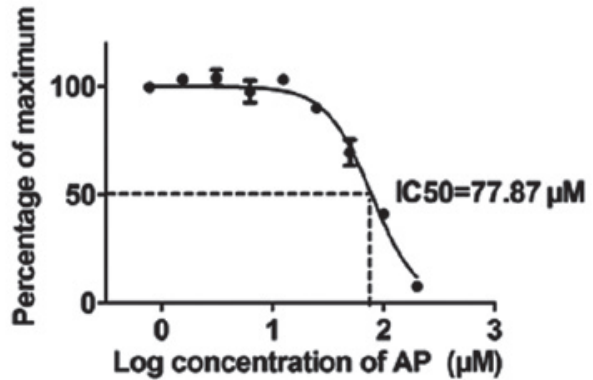

D

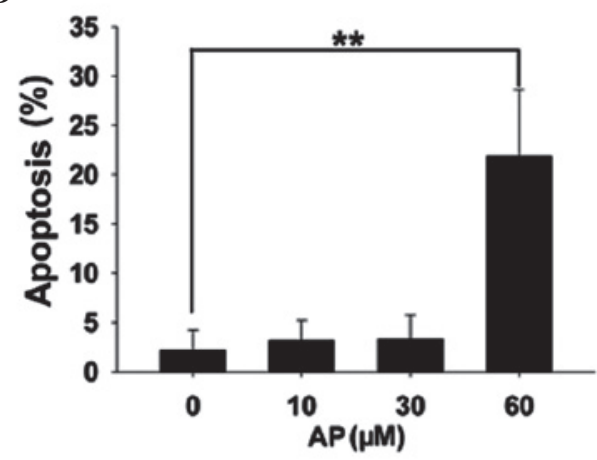

Figure 1. Andrographolide (AP) inhibits MDA-MB-231 breast cancer cell proliferation and promotes apoptosis at high concentrations. (A) Viability of AP-treated MDA-MB-231 cells. (B) The half-maximal inhibitory concentration $\left(\mathrm{IC}_{50}\right)$ of AP was $77.87 \mu \mathrm{M}$. (C) Flow cytometric analysis of AP-treated MDA-MB-231 cells. (D) Percentage of apoptotic cells. Results are presented as the mean \pm standard deviation of three independent experiments. ${ }^{*} \mathrm{P}<0.05$, ${ }^{* *} \mathrm{P}<0.01$ vs. $0 \mu \mathrm{M}$.

Valencia, CA, USA) following the manufacturer's instructions. cDNA was synthesized from $1 \mathrm{mg}$ of total RNA using reverse transcriptase (TaKaRa Biotechnology, Otsu, Japan). MMP-9 transcript expression levels were determined using the MiniOpticon Real-Time PCR system (Bio-Rad Laboratories, Hercules, CA, USA). qPCR was performed in a thermocycler (Biometra, T-Gradient Thermoblock, Germany) with a reaction volume of $10 \mu \mathrm{l}$ containing $0.03 \mu \mathrm{g}$ complementary DNA product, $2 \mu \mathrm{M}$ forward and reverse primers and the KAPA $^{\mathrm{TM}}$ SYBR $^{\circledR}$ FAST qPCR reagent (Kapa Biosystems, Wilmington, MA, USA). The primers used were as follows: Forward, 5'-GAACCAATCTCACCGACAGG-3', and reverse, 5'-GCCACCCGAGTGTAACCATA-3' for MMP-9; and forward, 5'-TCTGCTGGAAGGTGGACAGT-3', and reverse, 5'-CCTCTATGCCAACACAGTGC-3' for $\beta$-actin. Cycling conditions were as follows: 40 cycles of $95^{\circ} \mathrm{C}$ for $5 \mathrm{sec}$ and $60^{\circ} \mathrm{C}$ for $34 \mathrm{sec}$. $\beta$-actin was included as a reference control. The comparative $2^{-\Delta \Delta C t}$ method was used to calculate the relative expression of each gene (30).

$N F-\kappa B$-dependent luciferase reporter assay. The effect of AP on PMA-induced $N F-\kappa B$ activation was measured in MDA-MB-231 cells stably transfected with an NF- $\kappa$ B luciferase reporter construct (13). MDA-MB-231 cells were maintained in serum-free medium for $12 \mathrm{~h}$, pretreated with AP for $1 \mathrm{~h}$, followed by stimulation with PMA for $20 \mathrm{~h}$. Subsequently, the cell lysis was incubated with substrate (Promega, Madison, WI, USA) at room temperature for about $2 \mathrm{~min}$, luciferase activity was measured using the Promega Luciferase Assay System (Promega, Madison, WI, USA). Luciferase activity was measured and normalized to the internal control. Results were obtained from three independent experiments.
Western blotting. Western blotting was performed as previously described (30). The vehicle- or AP-treated cells were pretreated with PMA, washed twice in PBS and lysed in ice-cold lysis buffer (50 mM Tris pH 7.5, $150 \mathrm{mM} \mathrm{NaCl}, 1 \%$ Nonidet P-40, $0.1 \%$ SDS, $1 \%$ sodium deoxycholate) supplemented with phenylmethanesulfonyl fluoride (Shen Neng Bo Cai Corp., Shanghai, China). Lysates were maintained on ice for $30 \mathrm{~min}$ followed by centrifugation at $12,000 \mathrm{x} \mathrm{g}$ for $10 \mathrm{~min}$. Protein concentrations were determined using a bicinchoninic acid (BCA) assay (Thermo Scientific, Rockford, IL, USA). Equal amounts of protein were separated by $10 \%$ SDS-PAGE and electroblotted onto polyvinylidene fluoride membranes (Roche, Mannheim, Germany). The membranes were blocked with $5 \%(\mathrm{w} / \mathrm{v})$ skim milk solution for $1 \mathrm{~h}$ and probed with primary antibodies ( $\beta$-actin, 1:1,000; phospho-I $\kappa \mathrm{Ba}$, 1:1,000; IкBa, 1:1,000; and MMP-9, 1:1,000) at room temperature for $4 \mathrm{~h}$, followed by incubation with horseradish peroxidase-conjugated secondary antibodies (anti-human; Cell Signaling Technology, Inc.; 1:5,000) for $1 \mathrm{~h}$. Antibody reactivity was visualized using an Odyssey ${ }^{\circledR}$ Infrared Imaging system (Li-Cor, Lincoln, NE, USA).

Statistical analysis. Significant differences were determined with the Student's t-test using SPSS v13.0 software (SPSS Inc., Chicago, IL, USA). $\mathrm{P}<0.05$ was considered to indicate a statistically significant difference.

\section{Results}

$A P$ inhibits the proliferation of $M D A-M B-231$ breast cancer cells and promotes apoptosis at high concentrations. Following a 48-h culture, a CCK- 8 proliferation assay 
A

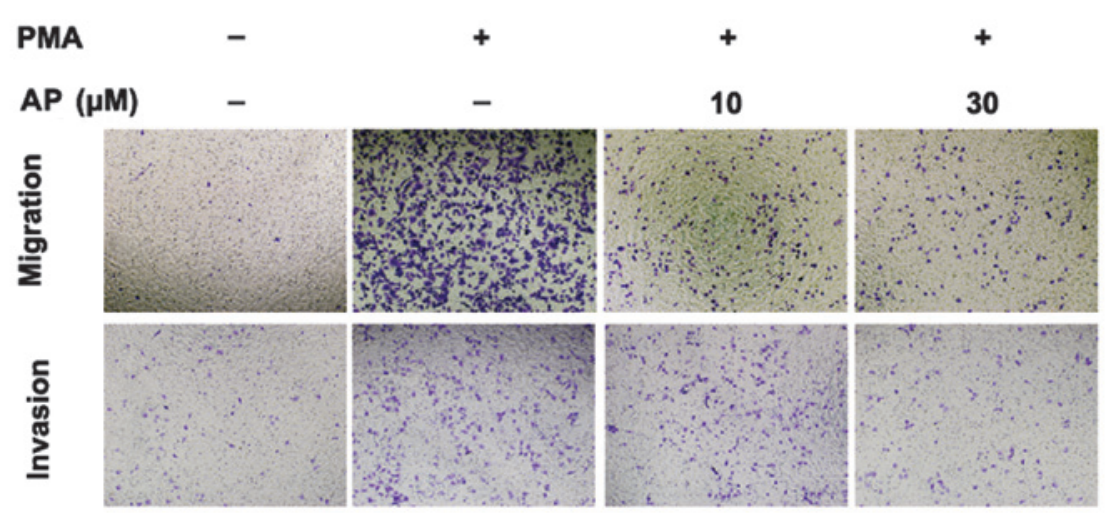

B

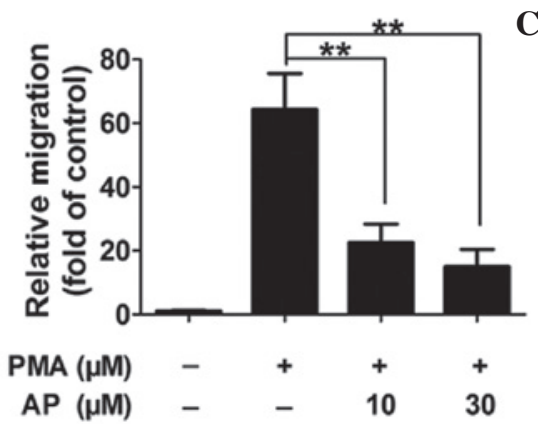

C

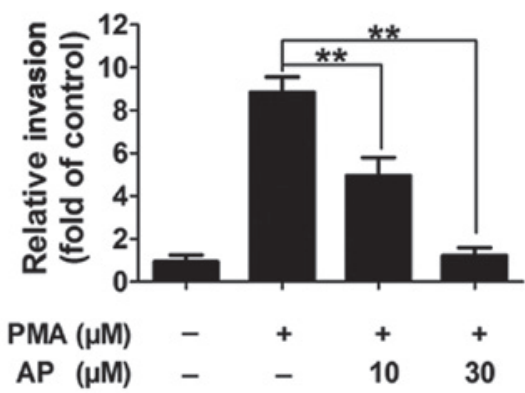

Figure 2. Andrographolide (AP) inhibits MDA-MB-231 breast cancer cell invasion and migration in a concentration-dependent manner at sub-lethal concentrations in vitro. (A) Membrane-associated, Liu-stained MDA-MB-231 breast cancer cells following treatment with AP and PMA. The numbers of (B) migrated and $(\mathrm{C})$ invasive cells were counted. Results were recorded at least three times in three independent experiments and are presented as the mean \pm standard deviation, $\mathrm{n}=3$. ${ }^{*} \mathrm{P}<0.05$ and ${ }^{* *} \mathrm{P}<0.01$

revealed that AP did not affect MDA-MB-231 cell proliferation at concentrations $\leq 30 \mu \mathrm{M}$ (Fig. 1A). AP significantly suppressed cell proliferation at concentrations $\geq 60 \mu \mathrm{M}$. The calculated $\mathrm{IC}_{50}$ for AP is $77.87 \mu \mathrm{M}$ (Fig. 1B). In cells treated with 10 or $30 \mu \mathrm{M}$ AP, the observed apoptotic effects were similar to those of the vehicle control; however, the higher concentration of $60 \mu \mathrm{M}$ AP induced apoptosis in $22 \%$ of cells (Fig. 1C and D). In order to exclude AP-mediated apoptosis, non-lethal concentrations $(\leq 30 \mu \mathrm{M})$ were used in subsequent experiments.

AP inhibits PMA-induced MDA-MB-231 cell migration and invasion in a concentration-dependent manner. PMA (80 $\mathrm{nM})$ induced increased levels of MDA-MB-231 cell migration and invasion compared with those observed in the untreated cells; however, pretreatment with AP inhibited the PMA-induced migration and invasion in a concentration-dependent manner (Fig. 2A). Quantitative analysis confirmed AP inhibition of cell migration and invasion at concentrations as low as $10 \mu \mathrm{M}$ (Fig. 2B and C).

AP inhibits breast cancer bone metastasis and osteolysis in vivo. To determine the effects of AP on breast cancer bone metastasis and cancer cell-induced osteolysis in vivo, a mouse xenotransplant model was used with human breast cancer cells (luciferase-labeled MDA-MB-231) (26,31). MDA-MB-231 cells were injected directly into the tibiae plateau via a percutaneous approach. After 28 days, bioluminescence was detected in the limbs of the control mice; however, the area and density of bioluminescence were reduced in the AP group compared with those in the control group (Fig. 3A), indicating that AP effectively suppressed breast cancer bone metastasis and growth in vivo. These observations were consistent with the results of the tumor volume assay (Fig. 3A). To confirm that osteolytic bone metastasis was blocked by AP, the osteolysis in the long bones of the hind legs was examined using radiography. AP significantly inhibited cancer cell-induced osteolysis (represented by radiolucency; Fig. 3A). TRAP staining (red) revealed numerous osteoclasts with intense activity in the vehicle-treated controls, however, in contrast, the number of osteoclasts was markedly reduced at the boundary in the treated mice (Fig. 3A), indicating that AP suppressed tumor-related osteolysis by inhibiting osteoclasts in vivo. All the results were confirmed using quantitative analysis (Fig. 3B). The proliferation-indicator Ki67 assay and the apoptosis-indicator TUNEL assay were also performed. Treatment of MDA-MB-231 tumor cells with AP $(50 \mathrm{mg} / \mathrm{kg})$ suppressed cellular proliferation compared with that in the control cells (Fig. 3C). The percentage of Ki67-positive cell nuclei was 7.1\% in the AP-treated group and $32.4 \%$ in the vehicle-treated group (Fig. 3D). The levels of apoptosis were significantly increased in the AP-treated group of MDA-MB-231 cell-associated breast tumors compared with those of the vehicle-treated group in the TUNEL assay (Fig. 3C and D). All in vivo data were consistent with the in vitro data, demonstrating that AP inhibits 
A

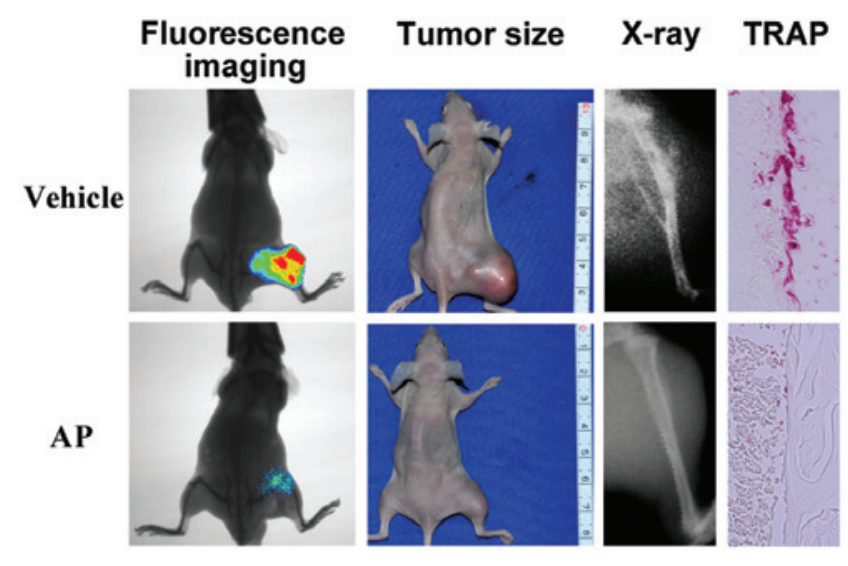

Vehicle

C

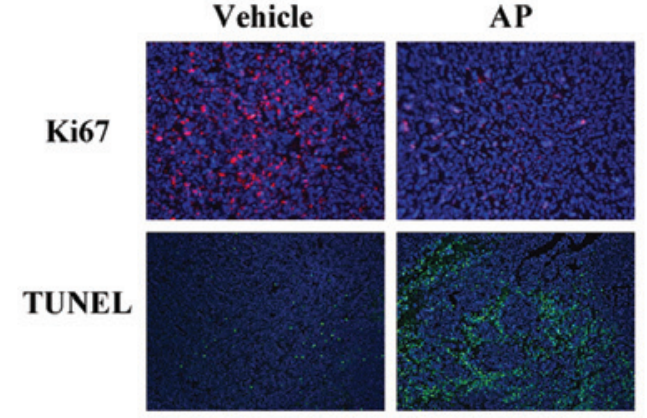

B
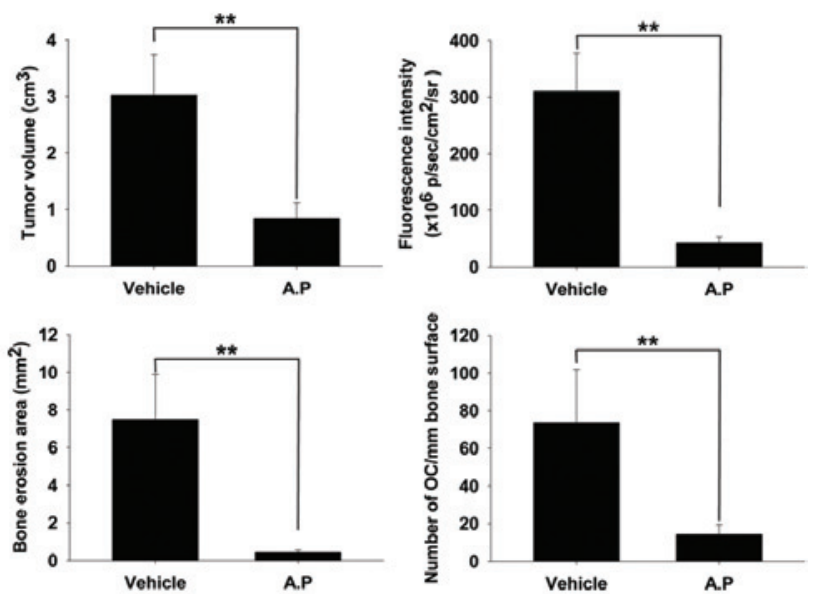

D
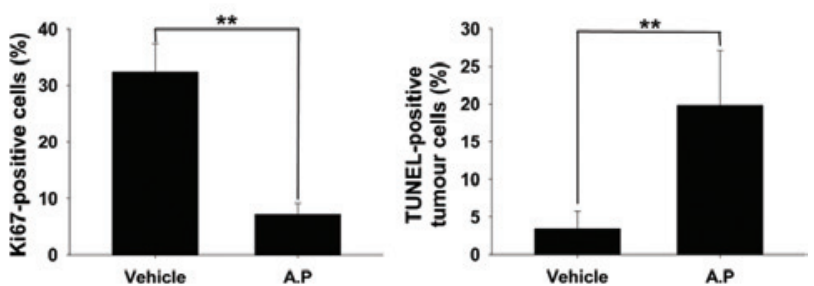

Figure 3. Bioluminescence of MDA-MB-231 human breast cancer cells in the anterior tuberosity of the proximal tibia in right limb of mice treated with vehicle $(0.9 \%$ sodium chloride, $\mathrm{n}=8$ ) or andrographolide (AP; $50 \mathrm{mg} / \mathrm{kg}$ body weight in vehicle, $\mathrm{n}=8)(\mathrm{A}) \mathrm{The}$ effects of $\mathrm{AP}$ on breast cancer-induced osteolytic lesions in mice as shown by X-ray imaging. Mouse tibia were collected from each group and sectioned for tartrate-resistant acid phosphatase (TRAP) staining (red signal). (B) Fluorescence intensity, tumor volume, bone erosion area, and number of osteoclasts (OC) were quantified and calculated. Experiments were performed in triplicate as three independent experiments. Results are presented as the mean \pm standard deviation (SD), $\mathrm{n}=3$. (C) Immunostaining for Ki67 and terminal deoxynucleotidyl transferase-mediated dUTP nick-end labeling (TUNEL). (D) Ki67- and TUNEL-positive tumor cells were counted and the percentages of positive cells were calculated. Experiments were performed in triplicate as three independent experiments and results are presented as the mean $\pm \mathrm{SD}, \mathrm{n}=3$. ${ }^{*} \mathrm{P}<0.05$ and ${ }^{* *} \mathrm{P}<0.01$
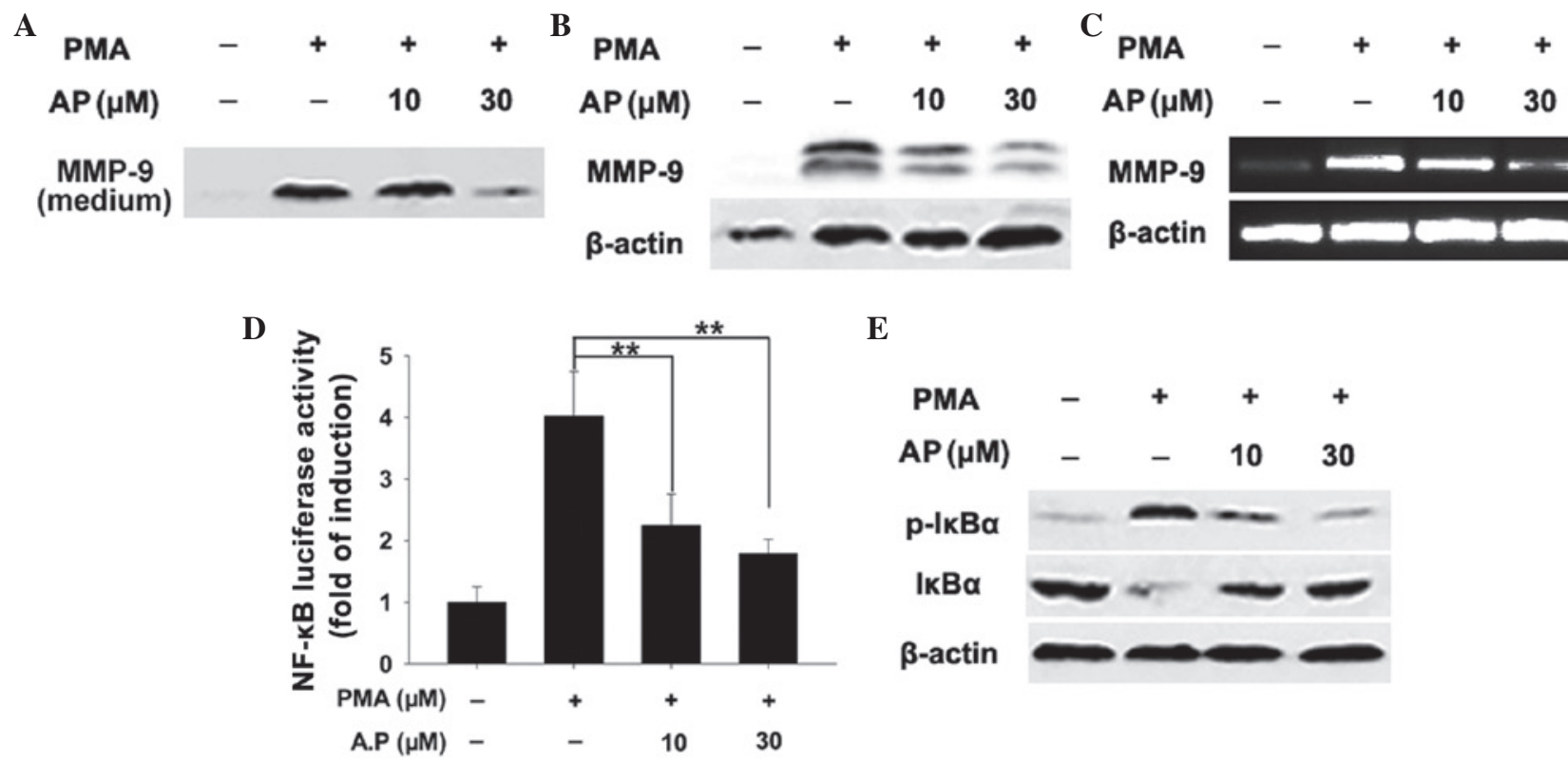

$\mathbf{E}$

MMP-9

及-actin

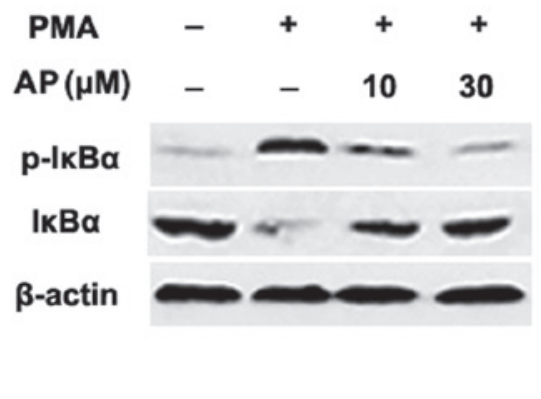

Figure 4. Andrographolide (AP) reduces phorbol 12-myristate 13-acetate (PMA)-stimulated matrix metalloproteinase (MMP)-9 expression via the suppression of the nuclear factor $\kappa \mathrm{B}$ (NF- $\kappa \mathrm{B}$ ) signaling pathway. (A) Immunodetection of MMP-9 in the media of AP- and PMA-treated MDA-MB-231 cells. (B) Western blotting of MMP-9 in AP- and PMA-treated MDA-MB-231 cells. (C) MMP-9 gene expression in cells exposed to AP and PMA as in (B). (D) Luciferase activity (NF- $\mathrm{kB}$ expression) in stably transfected MDA-MB-231 cells treated with AP and PMA. Results were obtained from three independent experiments

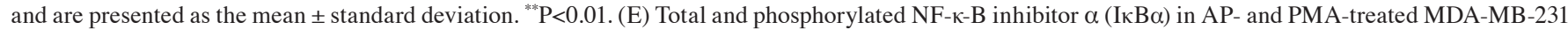
whole cell lysates. 
MDA-MB-231 cancer cell invasion and migration and suppresses tumor-induced osteolysis, possibly via inhibited osteoclast activity.

AP reduces PMA-stimulated MMP-9 secretion and expression. MMP-9 mediates tumor invasion and migration. In the current study, AP reduced the levels of MMP-9 secretion into the medium compared with those observed in the control cells (Fig. 4A). Consistent with the aforementioned findings, treatment of MDA-MB-231 cells with AP reduced PMA-stimulated MMP-9 protein expression in a concentration-dependent manner (Fig. 4B). qPCR revealed that PMA-induced MMP-9 mRNA expression decreased with AP treatment, indicating that AP-mediated inhibition of MMP-9 occurs at the transcriptional level (Fig. 4C).

AP suppresses $N F-\kappa B$ signaling. MMP-9 is highly inducible in response to various stimuli and the MMP-9 promoter contains a binding site for transcription factor $N F-\kappa B$ (12), hence it can be used to detect NF- $\kappa \mathrm{B}$ signaling. Measurement of NF- $\kappa \mathrm{B}$-dependent luciferase activity in MDA-MB-231 cells revealed that $\mathrm{PMA}$-induced $\mathrm{NF}-\kappa \mathrm{B}$ transcriptional activity was suppressed by AP (Fig. 4D). NF- $\kappa \mathrm{B}$ is normally sequestered in the cytoplasm in an inactive form associated with NF- $\mathrm{N}-\mathrm{B}$ inhibitor $\alpha(\mathrm{I} \kappa \mathrm{B} \alpha)$. Upon stimulation, the NF- $\kappa \mathrm{B}$ subunit is released via the phosphorylation and proteasomal degradation of $\mathrm{I} \kappa \mathrm{Ba}$ and translocated to the nucleus to initiate target gene transcription $(32,33)$. AP was observed to prevent the PMA-induced degradation of I $\kappa \mathrm{Ba}$ (Fig. 4E). As degradation of $\mathrm{I} \kappa \mathrm{B} \alpha$ is primarily the result of $\mathrm{I} \kappa \mathrm{B} \alpha$ phosphorylation (33), it was hypothesized that this effect may be due to the AP-induced inhibition of $\mathrm{I} \kappa \mathrm{B} \alpha$ phosphorylation. In the present study, AP caused a concentration-dependent reduction in PMA-induced $\mathrm{I} \kappa \mathrm{B} \alpha$ phosphorylation (Fig. $4 \mathrm{E}$ ). These results indicate that the inhibitory effect of AP on NF- $\mathrm{BB}$ signaling occurs via the inhibition of $\mathrm{I} \kappa \mathrm{Ba}$ phosphorylation, which in turn suppresses transcriptional activity. NF- $\kappa \mathrm{B}$ signaling activates MMP-9 transcription; thus, these results indicate that AP attenuates MMP-9 expression by inhibiting NF- $\kappa \mathrm{B}$ signaling.

\section{Discussion}

Previous studies have revealed the anti-cancer activity of AP $(17,18)$. The current study investigated the utility of AP in fighting aggressive MDA-MB-231 breast cancer cell invasion and bone metastasis. It was revealed that AP effectively inhibits breast cancer cell migration and invasion in vitro. In vivo, AP inhibits breast cancer bone metastasis, suppresses tumor growth and induces tumor apoptosis in bone. This inhibition was associated with the downregulation of MMP-9 expression levels.

MMP-9 expression levels are highly correlated with breast cancer cell invasion (34) and agents that downregulate MMP-9 have been observed to inhibit tumor invasion (9,35). MMP-9 is inducible by a number of stimuli; the MMP-9 promoter contains DNA-binding sites for $\mathrm{NF}-\kappa \mathrm{B}$, which regulates MMP-9 expression and secretion $(36,37)$. The transcription factor $\mathrm{NF}-\kappa \mathrm{B}$ regulates the transcription of genes associated with cancer development, tumor invasion and inflammation. It is a target for numerous biologically active phytochemicals, including curcumin, resveratrol and epigallocatechin gallate. Exposure of cells to stimuli such as PMA leads to IкBa phosphorylation and degradation, allowing $\mathrm{NF}-\kappa \mathrm{B}$ to translocate to the nucleus where it binds to the MMP-9 promotor and activates transcription (9).

In the current study, AP was revealed to inhibit PMA-induced MMP-9 expression. The specific response of MMP-9 indicates that its downregulation by AP is mediated through an upstream event. Concurrently, PMA was observed to increase the levels of $\mathrm{NF}-\kappa \mathrm{B}$ transcriptional activity, whilst AP inhibited PMA-induced NF- $\kappa \mathrm{B}$ transcriptional activity. These results confirm that $\mathrm{NF}-\kappa \mathrm{B}$ signaling is the molecular target for AP-induced inhibition of MMP-9 expression. Furthermore, the AP-induced reduction of PMA-stimulated NF- $\mathrm{B}$ transcriptional activity was identified to be due to the inhibition of $\mathrm{I}_{\kappa} \mathrm{Ba}$ phosphorylation and IкBa proteasomal degradation. However, the mechanisms by which AP inhibits the phosphorylation of I $\kappa$ Ba remain unclear.

In conclusion, AP-induced inhibition of I $\kappa \mathrm{Ba}$ phosphorylation was revealed to be the underlying mechanism of its effect on PMA-stimulated MDA-MB-231 cancer cell invasion. At sub-lethal concentrations, AP inhibits breast cancer cell migration and invasion via the downregulation of MMP-9 expression levels. The molecular mechanism by which AP inhibits MMP-9 expression involves the suppression of $\mathrm{NF}-\kappa \mathrm{B}$ activation. Tumor metastasis is often associated with poor prognosis and high mortality in breast cancer, prompting the requirement for the discovery and development of novel therapeutic strategies that target early tumor invasiveness and/or metastasis. AP reduces the invasiveness of highly aggressive MDA-MB-231 breast cancer cells in vitro, inhibits breast cancer bone metastasis, tumor growth, and tumor-induced osteolysis, and induces tumor apoptosis in vivo. It is thus a promising candidate therapeutic agent against breast cancer invasion and metastasis.

\section{Acknowledgements}

This study was supported by the Program for Innovative Research Team of Shanghai Municipal Education Commission (Phase I), a grant awarded for innovative research from Shanghai Municipal Education Commission (grant no. 13YZ031), a grant for scientific research from the National Natural Science Foundation for the Youth of China (grant no. 81201364), and a grant awarded by the Scientific Research Foundation for Returned Overseas Chinese Scholars from the State Human Resource Ministry, as well as the Key National Basic Research Program of China (grant no. 2012CB619101), the Major Basic Research of Science and Technology Commission of Shanghai Municipality (grant no. 11DJ1400303) and the Doctoral Innovation Foundation from Shanghai Jiaotong University School of Medicine (grant no. BXJ201330).

\section{References}

1. American Cancer Society: Breast cancer facts \& figures 2007-2008. American Cancer Society, Inc., Atlanta, GA, p1-13, 2007.

2. Gonzalez-Angulo AM, Morales-Vasquez F and Hortobagyi GN: Overview of resistance to systemic therapy in patients with breast cancer. In: Breast Cancer Chemosensitivity. Yu D and Hung MC (eds). Springer, New York, NY, pp 1-22, 2007. 
3. Lin CW, Shen SC, Hou WC, Yang LY and Chen YC: Heme oxygenase-1 inhibits breast cancer invasion via suppressing the expression of matrix metalloproteinase-9. Mol Cancer Ther 7: 1195-1206, 2008.

4. Gialeli C, Theocharis AD and Karamanos NK: Roles of matrix metalloproteinases in cancer progression and their pharmacological targeting. FEBS J 278: 16-27, 2011.

5. Kessenbrock K, Plaks V and Werb Z: Matrix metalloproteinases: regulators of the tumor microenvironment. Cell 141: 52-67, 2010

6. Deryugina EI and Quigley JP: Pleiotropic roles of matrix metalloproteinases in tumor angiogenesis: contrasting, overlapping and compensatory functions. Biochim Biophys Acta 1803 103-120, 2010

7. Shuman Moss LA, Jensen-Taubman S and Stetler-Stevenson WG Matrix metalloproteinases: changing roles in tumor progression and metastasis. Am J Pathol 181: 1895-1899, 2012.

8. Brinckerhoff CE and Matrisian LM: Matrix metalloproteinases: a tail of a frog that became a prince. Nat Rev Mol Cell Biol 3: 207-214, 2002

9. Overall CM and López-Otín C: Strategies for MMP inhibition in cancer: innovations for the post-trial era. Nat Rev Cancer 2: 657-672, 2002

10. Chakraborti S, Mandal M, Das S, Mandal A and Chakraborti T: Regulation of matrix metalloproteinases: an overview. Mol Cell Biochem 253: 269-285, 2003.

11. Egeblad M and Werb Z: New functions for the matrix metalloproteinases in cancer progression. Nat Rev Cancer 2: 161-174, 2002

12. Sato $\mathrm{H}$ and Seiki M: Regulatory mechanism of $92 \mathrm{kDa}$ type IV collagenase gene expression which is associated with invasiveness of tumor cells. Oncogene 8: 395-405, 1993

13. Ling H, Zhang Y, Ng KY and Chew EH: Pachymic acid impairs breast cancer cell invasion by suppressing nuclear factor- $\kappa \mathrm{B}$-dependent matrix metalloproteinase-9 expression. Breast Cancer Res Treat 126: 609-620, 2011

14. Weng CJ, Chau CF, Hsieh YS, Yang SF and Yen GC: Lucidenic acid inhibits PMA-induced invasion of human hepatoma cells through inactivating MAPK/ERK signal transduction pathway and reducing binding activities of NF-kappaB and AP-1. Carcinogenesis 29: 147-156, 2008.

15. Coon JT and Ernst E: Andrographis paniculata in the treatment of upper respiratory tract infections: a systematic review of safety and efficacy. Planta Med 70: 293-298, 2004.

16. Jiang X, Yu P, Jiang J, et al: Synthesis and evaluation of antibacterial activities of andrographolide analogues. Eur J Med Chem 44: 2936-2943, 2009.

17. Wang LJ, Zhou X, Wang W, et al: Andrographolide inhibits oral squamous cell carcinogenesis through NF- $\mathrm{KB}$ inactivation. J Dental Res 90: 1246-1252, 2011.

18. Rajagopal S, Kumar RA, Deevi DS, Satyanarayana C and Rajagopalan R: Andrographolide, a potential cancer therapeutic agent isolated from Andrographis paniculata. J Exp Ther Oncol 3: 147-158, 2003.

19. Chiou WF, Lin JJ and Chen CF: Andrographolide suppresses the expression of inducible nitric oxide synthase in macrophage and restores the vasoconstriction in rat aorta treated with lipopolysaccharide. Br J Pharmacol 125: 327-334, 1998.

20. Shen YC, Chen CF and Chiou WF: Andrographolide prevents oxygen radical production by human neutrophils: possible mechanism(s) involved in its anti-inflammatory effect. Br J Pharmacol 135: 399-406, 2002.
21. Trivedi NP, Rawal UM and Patel BP: Potency of andrographolide as an antitumor compound in BHC-induced liver damage. Integr Cancer Ther 8: 177-189, 2009.

22. Handa SS and Sharma A: Hepatoprotective activity of andrographolide against galactosamine \& paracetamol intoxication in rats. Indian J Med Res 92: 284-292, 1990.

23. Harjotaruno S, Widyawaruyanti A, Sismindari and Zaini NC: Apoptosis inducing effect of andrographolide on TF-47 human breast cancer cell line. Afr J Tradit Complement Altern Med 4: 345-351, 2007.

24. Kumar S, Patil SH, Sharma P, et al: Andrographolide inhibits osteopontin expression and breast tumor growth through down regulation of PI3 kinase/Akt signaling pathway. Curr Mol Med 12: 952-966, 2012.

25. Chao CY, Lii CK, Hsu YT, et al: Induction of heme oxygenase-1 and inhibition of TPA-induced matrix metalloproteinase-9 expression by andrographolide in MCF-7 human breast cancer cells. Carcinogenesis 34: 1843-1851 2013.

26. Ooi LL, Zhou H, Kalak R, et al: Vitamin D deficiency promotes human breast cancer growth in a murine model of bone metastasis. Cancer Res 70: 1835-1844, 2010.

27. Zheng Y, Zhou H, Modzelewski JR, et al: Accelerated bone resorption, due to dietary calcium deficiency, promotes breast cancer tumor growth in bone. Cancer Res 67: 9542-9548, 2007.

28. Traxler P, Allegrini PR, Brandt R, et al: AEE788: a dual family epidermal growth factor receptor/ErbB2 and vascular endothelial growth factor receptor tyrosine kinase inhibitor with antitumor and antiangiogenic activity. Cancer Res 64: 4931-4941, 2004.

29. Wu W, Onn A, Isobe T, et al: Targeted therapy of orthotopic human lung cancer by combined vascular endothelial growth factor and epidermal growth factor receptor signaling blockade. Mol Cancer Ther 6: 471-483, 2007.

30. Li H, Zhai Z, Liu G, et al: Sanguinarine inhibits osteoclast formation and bone resorption via suppressing RANKL-induced activation of NF- $\mathrm{KB}$ and ERK signaling pathways. Biochem Biophys Res Commun 430: 951-956, 2013.

31. Ooi LL, Zheng Y, Zhou H, et al: Vitamin D deficiency promotes growth of MCF-7 human breast cancer in a rodent model of osteosclerotic bone metastasis. Bone 47: 795-803, 2010.

32. Ghosh S and Hayden MS: New regulators of NF-kappaB in inflammation. Nat Rev Immunol 8: 837-848, 2008.

33. Ghosh S and Baltimore D: Activation in vitro of NF-kappa B by phosphorylation of its inhibitor I kappa B. Nature 344: 678-682, 1990.

34. Duffy MJ, Maguire TM, Hill A, McDermott E and O'Higgins N: Metalloproteinases: role in breast carcinogenesis, invasion and metastasis. Breast Cancer Res 2: 252-257, 2000.

35. Park JM, Kim A, Oh JH and Chung AS: Methylseleninic acid inhibits PMA-stimulated pro-MMP-2 activation mediated by MT1-MMP expression and further tumor invasion through suppression of NF-kappaB activation. Carcinogenesis 28: 837-847, 2007.

36. Takada Y, Ichikawa H, Badmaev V and Aggarwal BB: Acetyl-11-keto-beta-boswellic acid potentiates apoptosis, inhibits invasion, and abolishes osteoclastogenesis by suppressing NF-kappa B and NF-kappa B-regulated gene expression. J Immunol 176: 3127-3140, 2006

37. Huang Q, Shen HM and Ong CN: Inhibitory effect of emodin on tumor invasion through suppression of activator protein-1 and nuclear factor-kappaB. Biochem Pharmacol 68: 361-371, 2004. 